\title{
Effect of extraction method on the antioxidative activity of ground elder (Aegopodium podagraria L.)
}

\author{
Agnieszka Wróblewska ${ }^{1 *}$, Katarzyna Janda ${ }^{2 *}$, Edyta Makuch ${ }^{1}$, Marika Walasek ${ }^{1}$, Piotr Miądlicki ${ }^{1}$, \\ Karolina Jakubczyk ${ }^{2}$
}

\author{
${ }^{1}$ West Pomeranian University of Technology, Szczecin, Faculty of Chemical Technology and Engineering, Institute of \\ Organic Chemical Technology, Piastów Ave. 42, 71-065 Szczecin, Poland \\ ${ }^{2}$ Pomeranian Medical University, Department of Human Nutrition and Metabolomics, Broniewskiego Street 24, \\ 71-460 Szczecin, Poland \\ "Corresponding authors: e-mail: agnieszka.wroblewska@zut.edu.pl, kjanda4@gmail.com
}

\begin{abstract}
In this work the studies on the antioxidative properties of extracts from various morphotic parts of the ground elder (leaves, rhizomes, seeds and flowers) were presented. Moreover, the effect of different extraction methods (ultrasonic assisted extractions, extraction in a Soxhlet apparatus, extraction at the boiling point of the solvent used), solvent and its amount, and extraction time on the antioxidative properties of the obtained extracts were tested. The studies showed that all parts of ground elder can show radical scavenging activity, and it depends mainly on the method of extraction and extraction time. But the most beneficial is ultrasonic assisted extraction which used lower amount of solvent (ethanol). In case of all parts of the ground elder (leaves, rhizomes, seeds and flowers) it allows to obtain very high values of the antioxidant capacity (above 90\%) for very short extraction time amounted to $20-40$ minutes.
\end{abstract}

Keywords: Ground elder, methods of extractions, antioxidant activity, DPPH radical.

\section{INTRODUCTION}

In recent years, much attention was paid to the oxidative stress. In normal conditions there is a balance between the formation of reactive oxygen species and their removal, and the effect of these molecules depends on concentration and duration of action. Low concentrations of these molecules have physiological functions, while higher concentrations affect the oxidative balance disorder ${ }^{1-3}$. An inefficient repair system and intensified ROS (reactive oxygen species) synthesis causes oxidative stress what causes oxidation of cell membranes, change of structure, modification of protein functions as well as DNA damage or acceleration of aging processes, which may contribute to the creation of mutations. These changes can lead to the development of many diseases such as cancers, neurodegenerative disorders eg. Alzheimer's disease, atherosclerosis, coronary heart diseases, cataracts and aging ${ }^{4-8}$.

Plants are a rich source of bioactive substances with pro-health effects. Antioxidants in plants may protect cells against the effects of free radicals. Search for new sources of natural antioxidants seems to be beneficial in health protection. Some of the extraction methods presented in this article are used, for example, to obtain orange oil from waste orange peel (also industrially this oil is obtained by extraction from orange peels). This oil contains more than $97 \% \mathrm{R}(+)$-limonene. In addition, extracts from cumin (obtaining s-carvone) and from young cones and branches of coniferous trees, e.g. pine (obtaining alpha-pinene) are also obtained. A plant that has been forgotten in modern phytotherapy with a promising therapeutic potential seems to be the ground elder.

The ground elder (Aegopodium podagraria L.) is a widespread plant of the Apiaceae family growing in Europe, Caucasus, Southwestern Asia and Siberia, 10. In folk medicine, the ground elder was used to treat gout, arthritis, kidney and bladder inflammations, hemorrhoids and it was used to accelerate the healing of wounds ${ }^{11,12}$.
The ground elder is a weed and ornamental plant and the leaves are also edible. Although its chemical content has not been fully researched, it is known that its main group of compounds consists of polyacetylenes (falcarinol and falcarindiol $)^{13-15}$.Moreover, essential oils of the monoterpenes and sesquiterpenes groups were isolated from this plant, along with coumarins and polyphenolic compounds ${ }^{15-20}$. This plant also contains micro and macro elements such as $\mathrm{Zn}, \mathrm{Cu}, \mathrm{Cr}, \mathrm{Mn}, \mathrm{Co}, \mathrm{K}$ and also ascorbic acid (vitamin C) and $\alpha$-tocopherol (vitamin E) ${ }^{14}$. Preparations made from the ground elder have antimicrobial properties, too ${ }^{11,21}$. Falcarinol isolated from this plant has strong inhibitory properties against the inflammatory enzyme COX-1 ${ }^{15}$. It also affects the nervous system and facilitate the functioning of metformin - a type of medicine used in the treatment of type 2 diabetes $^{22-28}$.

Despite the content of many bioactive compounds with antioxidant properties such as phenolic acids and flavonoids, there are no studies confirming the antioxidative properties of the extracts from various morphotic parts of the ground elder and the effect of different extraction methods on these properties. Therefore, the aim of this study was to investigate various morphic parts of the ground elder (leaves, rhizomes, seeds and flowers) using different extracting methods and solvents to determine their radical scavenging activity.

\section{EXPERIMENTAL}

\section{Raw materials}

The following chemical reagents were used for the tests: ethanol (analytical grade, Chempur), acetone (analytical grade, Chempur), and DPPH (2,2-diphenyl-1-picrylhydrazyl, Sigma Aldrich).

\section{Preparation of plant material}

The plant material of Aegopodium podagraria L. (rhizome, leaves, flowers, and seeds) was taken from 
areas located in the West Pomeranian Voivodeship in north-western Poland, from spring to autumn 2015. Directly after picking, the plant material was cleaned, then frozen at the temperature $-20^{\circ} \mathrm{C}$ and lyophilized in the apparatus Alpha 1-2 LD plus (the pressure of $0.735 \mathrm{mmHg}$, temperature $-20^{\circ} \mathrm{C}$ ). The dried material was homogenized (homogenizer for food analysis FOSS 2094) and was used to prepare extracts.

\section{Methods of the isolation of active ingredients from se- lected parts of plant material}

The following methods were used to isolate active ingredients from selected parts of ground elder: ultrasonic assisted extractions (weight ratio of plant material to ethanol 1:30 (extraction 1) and 1:20 (extraction 2)), extraction in a Soxhlet apparatus (weight ratio of plant material to acetone 1:30 (extraction 3)), extraction at the boiling point of the solvent used (weight ratio of plant material to acetone 1:30 (extraction 4)).

\section{The method of conducting the isolation of active ingre- dients by extraction methods}

Extraction 1 was carried out in a $100.0 \mathrm{~cm}^{3}$ glass bottle, into which $1.166 \mathrm{~g}$ of plant material (that was previously ground) was introduced along with $35.0 \mathrm{~g}$ of ethanol. The glass bottle was screwed on with a cap equipped with a venting needle, placed in an ultrasonic bath and extracted for 6 hours.

Extraction 2 was carried out in the same way. To a $100.0 \mathrm{~cm}^{3}$ glass bottle was introduced $1.750 \mathrm{~g}$ of plant material (that was previously ground) together with 35.0 $\mathrm{g}$ of ethanol, in order to keep the weight ratio of plant material to ethanol equal to $1: 20$.

Extraction 3 was carried out in the following manner: $2.332 \mathrm{~g}$ of plant material (that was previously ground) was placed in a thimble, which was then transferred to a Soxhlet apparatus. The Soxlet apparatus was placed between a $250.0 \mathrm{~cm}^{3}$ round bottom flask containing 70.0 $\mathrm{g}$ of acetone and a reflux condenser. The contents of the round bottom flask were boiled and extracted for 6 hours.

Extraction 4 was carried out in a glass apparatus consisting of a $250.0 \mathrm{~cm}^{3}$ round bottom flask equipped with a thermometer and a straight condenser into which $2.332 \mathrm{~g}$ of plant material (that was previously ground) together with $70.0 \mathrm{~g}$ of acetone were introduced. The contents of the round bottom flask were boiled and extracted for 6 hours.

Ethanol is a solvent very often used to obtain extracts from plant material. That's why we decided to use it. Not all compounds, however, dissolve well in ethanol, so we also used acetone in our study. In addition, acetone (boiling point $56^{\circ} \mathrm{C}$ ), which has a lower boiling point than ethanol $\left(78^{\circ} \mathrm{C}\right)$ seemed better to the methods associated with evaporation of the solvent. When selecting a solvent, the stability of the extracted compounds, which are often unstable at elevated temperature, should be taken into account. Therefore, it was decided to investigate the effect of 2 solvents differing in boiling points.

During the extraction, samples were taken to determine the antioxidant properties of extracts by the method of reducing the DPPH radical. The obtained results are presented in Table 1.
Determination of the antioxidant properties of extracts by the method of reduction of the DPPH radical

Measurements of the antioxidative properties of obtained extracts were made by the spectrophotometric method, with the Spectroquant Pharo 300 MERCK apparatus, at the wavelength of $\lambda=515 \mathrm{~nm}$. The DPPH reagent was used for the determination of the antioxidant properties because it has a stable free radical with unpaired electrons on the valence coating.

First, the spectrophotometer was calibrated using ethanol as a solvent. A DPPH solution in ethanol was then made by addition the DPPH reagent so that the absorbance of the resulting solution was about 1.000 \pm 0.020 (at wavelength $\lambda=515 \mathrm{~nm}$ ). The DPPH in ethanol solutions (similar to the DPPH reagent) form stable cation radicals with a dark violet color at a maximum absorbance in the range of $515 \mathrm{~nm}$ to $517 \mathrm{~nm}$. As a result of contact of the ethanol DPPH solution with the extract characterized by antioxidant properties, the discoloration of the dark purple color of the DPPH solution and decrease of the absorbance of the tested solution are observed. The determinations were carried out as follows: $225 \mu \mathrm{l}$ of the extract being tested and $4275 \mu \mathrm{l}$ of the DPPH solution were placed in a plastic tube, and then the tube was sealed with a stopper and placed in a dark place for ten minutes incubation at room temperature. After this time a measurement was made. Each sample was tested three times, then the average absorbance value $\left(\mathrm{A}_{\text {ave. }}\right)$ For each of them was calculated and the average percentage of scavenging of the DPPH radical $(\%$ ave. $)$, according to the following formula:

Reduction of the DPPH radical $[\%]=\left(\mathrm{A}_{0}-\mathrm{A}_{1}\right) / \mathrm{A}_{0}$ * $100 \%$

where:

$\mathrm{A}_{0}$ - absorbance of the DPPH radical solution,

$\mathrm{A}_{1}$ - absorbance of a DPPH radical solution containing the tested extract

The obtained test results are presented in Table 1 .

\section{Statistical analysis}

In all the experiments, three samples were analysed, and all the assays were carried out at least in triplicate. The statistical analysis was performed using Stat Soft Statistica 13.0 and Microsoft Excel 2007. The results are expressed as mean values and standard deviation (SD). For percent of inhibition DPPH was used one-way analysis of variance (ANOVA), Tukey post-hoc test. Differences were considered significant at $\mathrm{p} \leq 0.05$.

\section{RESULTS AND DISCUSION}

Goutweed contains many biologically active substances with wide spectrum of activity. However, the available literature contains not enough information about the antioxidant properties of this plant. Our research shows that the antioxidant potential of plant extracts is high and ranges from 30.5 to $94.5 \%$ of DPPH depending on the extraction method, time and part of the plant.

Table 1 presents the results of the measurements of the antioxidant capacity of the ground elder extracts, which was examined by the reduction of the DPPH radical. 
Table 1. Antioxidative capacity of ground elder extracts measured by DPPH radical reduction

\begin{tabular}{|c|c|c|c|c|c|}
\hline Method of extraction & $\begin{array}{l}\text { Sample } \\
\text { number }\end{array}$ & $\begin{array}{l}\text { Type of plant } \\
\text { material }\end{array}$ & $\begin{array}{c}\text { Extraction } \\
\text { time } \\
\text { [min] }\end{array}$ & $\begin{array}{c}\text { Average } \\
\text { absorbance value } \\
{\left[\mathrm{A}_{\text {Ave. }}\right]}\end{array}$ & $\begin{array}{c}\text { Average percentage of } \\
\text { scavenging of the DPPH radical } \\
{[\% \text { Ave. }]}\end{array}$ \\
\hline \multirow{20}{*}{$\begin{array}{l}\text { Ultrasonic assisted extractions } \\
\text { (extraction } 1 \text { - weight ratio of } \\
\text { plant material to ethanol } 1: 30 \text { ) }\end{array}$} & $\mathrm{E}-1-1$ & \multirow{5}{*}{ Leaves } & 20 & & - \\
\hline & $E-1-2$ & & 40 & 0.369 & 63.1 \\
\hline & E-1-3 & & 60 & 0.456 & 54.4 \\
\hline & E-1-4 & & 120 & 0.127 & 87.2 \\
\hline & E-1-5 & & 360 & 0.186 & 81.5 \\
\hline & $E-2-1$ & \multirow{5}{*}{ Rhizomes } & 20 & 0.462 & 53.9 \\
\hline & E-2-2 & & 40 & 0.468 & 53.2 \\
\hline & $E-2-3$ & & 60 & 0.374 & 62.6 \\
\hline & E-2-4 & & 120 & 0.090 & 91.0 \\
\hline & E-2-5 & & 360 & - & - \\
\hline & E-3-1 & \multirow{5}{*}{ Seeds } & 20 & - & - \\
\hline & E-3-2 & & 40 & 0.569 & 43.1 \\
\hline & E-3-3 & & 60 & 0.605 & 39.4 \\
\hline & E-3-4 & & 120 & 0.135 & 87.5 \\
\hline & E-3-5 & & 360 & - & - \\
\hline & E-4-1 & \multirow{5}{*}{ Flowers } & 20 & 0.322 & 67.8 \\
\hline & E-4-2 & & 40 & 0.083 & 91.7 \\
\hline & E-4-3 & & 60 & 0.132 & 86.8 \\
\hline & E-4-4 & & 120 & - & - \\
\hline & E-4-5 & & 360 & - & - \\
\hline \multirow{20}{*}{$\begin{array}{l}\text { Ultrasonic assisted extractions } \\
\text { (extraction } 2 \text { - weight ratio of } \\
\text { plant material to ethanol } 1: 20 \text { ) }\end{array}$} & E-5-1 & \multirow{5}{*}{ Leaves } & 20 & 0.685 & 31.5 \\
\hline & E-5-2 & & 40 & 0.907 & 93.0 \\
\hline & $E-5-3$ & & 60 & 0.226 & 77.4 \\
\hline & E-5-4 & & 120 & 0.540 & 46.0 \\
\hline & E-5-5 & & 360 & - & - \\
\hline & E-6-1 & \multirow{5}{*}{ Rhizomes } & 20 & 0.055 & 94.5 \\
\hline & E-6-2 & & 40 & 0.080 & 92.0 \\
\hline & E-6-3 & & 60 & 0.573 & 42.7 \\
\hline & E-6-4 & & 120 & - & - \\
\hline & E-6-5 & & 360 & - & - \\
\hline & E-7-1 & \multirow{5}{*}{ Seeds } & 20 & 0.144 & 85.6 \\
\hline & E-7-2 & & 40 & 0.096 & 90.4 \\
\hline & E-7-3 & & 60 & 0.250 & 75.0 \\
\hline & E-7-4 & & 120 & - & - \\
\hline & E-7-5 & & 360 & - & - \\
\hline & E-8-1 & \multirow{5}{*}{ Flowers } & 20 & 0.094 & 90.6 \\
\hline & E-8-2 & & 40 & - & - \\
\hline & E-8-3 & & 60 & - & - \\
\hline & E-8-4 & & 120 & - & - \\
\hline & E-8-5 & & 360 & - & - \\
\hline \multirow{4}{*}{$\begin{array}{c}\text { Extraction in the Soxhlet } \\
\text { appparatus } \\
\text { (extraction } 3 \text { - weight ratio of } \\
\text { plant material to acetone 1:30) }\end{array}$} & E-9-1 & Leaves & \multirow{4}{*}{360} & 0.088 & 91.2 \\
\hline & E-10-1 & Rhizomes & & 0.172 & 82.5 \\
\hline & E-11-1 & Seeds & & 0.488 & 51.2 \\
\hline & $E-12-1$ & Flowers & & 0.448 & 55.2 \\
\hline \multirow{4}{*}{$\begin{array}{l}\text { Extraction at the boiling point } \\
\text { of the solvent used } \\
\text { (extraction } 4 \text { - weight ratio of } \\
\text { plant material to acetone } 1: 30 \text { ) }\end{array}$} & E-13-1 & Leaves & \multirow{4}{*}{360} & 0.782 & 21.8 \\
\hline & E-14-1 & Rhizomes & & 0.111 & 88.9 \\
\hline & E-15-1 & Seeds & & 0.910 & 90.0 \\
\hline & E-16-1 & Flowers & & - & - \\
\hline
\end{tabular}

"-" this means that there was too little of the solution to perform an antioxidative capacity test

The comparison of the results obtained for leaves during ultrasonic assisted extraction using extraction 1 and 2 shows that in general the antioxidant capacity of extracts obtained in extraction 1 (in which more ethanol was used) was higher but it required a longer extraction time. In extraction 1 during prolongation the extraction time from 20 to 120 minutes the antioxidant capacity gradually increased from value $63.1 \%$ to $87.2 \%$ and next slightly decreased to value $81.5 \%$ (extraction time 120 minutes). In extraction 2 for the extraction time of 20 minutes the antioxidant capacity amounted to $31.5 \%$, next raised to $93.0 \%$ (extraction time 40 minutes) and then decreased to $46.0 \%$ (extraction time 120 minutes). Taking into account the time of extraction and value of the antioxidant capacity the most beneficial was extraction 2 and extraction time amounted to 40 minutes.
For rhizomes in extraction 1 the antioxidant capacity raised from $53.9 \%$ to $91.0 \%$ in the range of extraction time from 20 to 360 minutes. In the case of extraction 2 the antioxidant capacity decreased from $94.5 \%$ to $42.7 \%$. In general, for higher quantities of extraction agent (ethanol), higher values of antioxidant capacity for longer esterification times (360 minutes) were obtained. For extraction 2, the highest antioxidant capacity was achieved for the shortest extraction time - 20 minutes. Hence, extraction 2, using a smaller amount of extraction medium, seems to be more beneficial.

The same direction of changes of the antioxidant capacity was observed for seeds. For extraction 1 the prolongation the extraction time caused the raising in the values of the antioxidant capacity from $43.2 \%$ to $87.5 \%$. In extraction 2 during prolongation the extraction time the antioxidant capacity decreased from $85.6 \%$ to 
$75 \%$. In general, the most beneficial was extraction 2 which allowed to obtain higher values of the antioxidant capacity.

For flowers the antioxidant capacity also raised during tests with help of the extraction 1 (from $67.8 \%$ to $86.8 \%$ ), and during tests with help of the extraction 2 it achieved the value of 90.6 for the shortest extraction time.

The comparison the results of studies on the extractions 1 and 2 showed that the extraction 2 was the most beneficial for all studied parts of ground elder. It allowed to obtain high values of the antioxidant capacity for short extraction time.

Considering the preparation of extracts using method 1, it was shown that the antioxidant potential of the extracts obtained from particular parts of ground elder differed statistically significantly between each other depending on the time and temperature of extraction In extraction 2 , statistically significant differences between the extractions depending on the time and temperature of extraction were shown only for those obtained from leaves, rhizomes and seeds.

In the extraction in a Soxhlet apparatus (weight ratio of plant material to acetone 1:30 (extraction 3), extraction time 360 minutes) the highest value of the antioxidant capacity was obtained for herbs (91.2\%), slightly lower for rhizomes $(82.5 \%)$, and for seeds and flowers the values of the antioxidant capacity were considerably lower and amounted to 51.2 and $55.2 \%$, respectively. The comparison showed that very similar values of the antioxidant capacity were obtained in extraction 1 but from these three described in detail extractions the most beneficial is still extraction 2 which needed very short time of extraction to obtain the highest value of the antioxidant capacity. Statistical analysis showed that the extracts obtained using the Soxhlet method differed significantly depending on the morphological part of the plant.

During extraction at the boiling point of the solvent used (weight ratio of plant material to acetone 1:30 (extraction 4), extraction time 360 minutes) the highest value of the antioxidant capacity was obtained for rhizomes and seeds: $88.9 \%$ and $90.0 \%$, respectively. The value of the antioxidant capacity obtained for leaves was considerably lower and amounted to $21.8 \%$. Statistical analysis showed that the antioxidant capacity of leaf extracts differed significantly from those from rhizomes and from leaves and seeds; whereas the difference between the antioxidative potential of rhizome and seed extracts was not significant.

Figure 1 presents a comparison of the antioxidant activity of extracts from the ground elder depending on the conditions of extraction. Statistical analysis showed that between all presented values the differences were statistically significant.

Figure 2 presents a comparison of antioxidant activity of extracts from rhizomes of ground elder depending on the conditions of extraction. Statistical analysis showed that between all presented values the differences were statistically significant.

Figure 3 presents a comparison of the antioxidant activity of the ground elder seed extracts depending on the extraction conditions. Statistical analysis showed that only between the antioxidant potential of the extract obtained

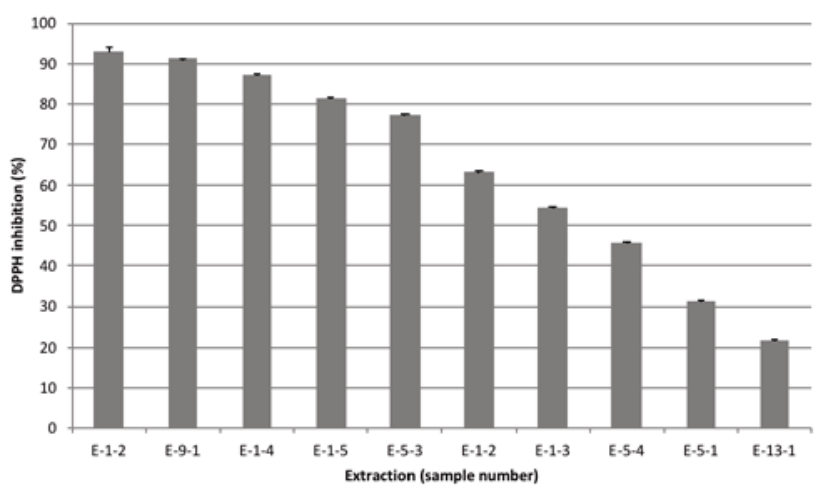

Figure 1. The comparison of antioxidant activity extracts of leaves ground elder depending on the method of extraction (full explanation of the extract designations can be found in Table 1)

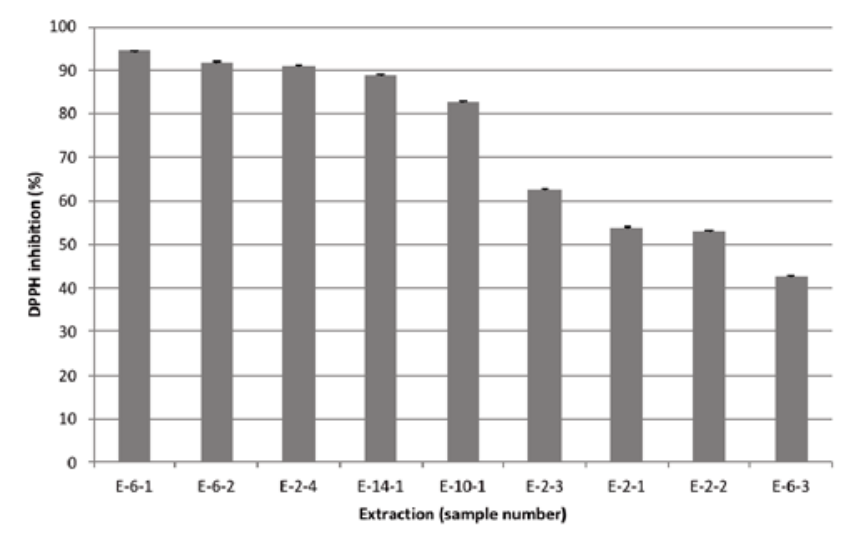

Figure 2. The comparison of antioxidant activity extracts of rhizomes of ground elder depending on the method of extraction (full explanation of the extract designations can be found in Table 1)

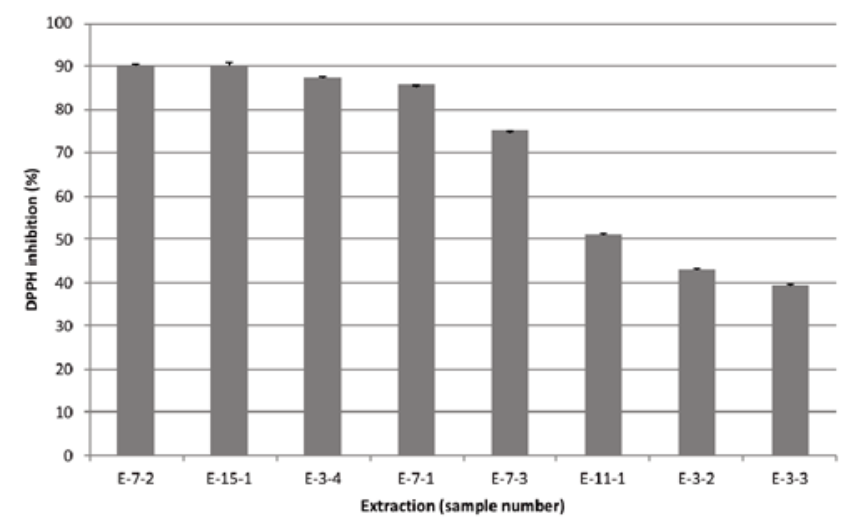

Figure 3. The comparison of antioxidant activity extracts of seeds of ground elder depending on the method of extraction (full explanation of the extract designations can be found in Table 1)

by extraction 1 (sample number E-7-2) and extraction 4 (sample number E-15-2) the differences were statistically insignificant; in other cases, the antioxidant potential of the extracts was significantly different.

Figure 4 presents a comparison of the antioxidant activity of the ground elder flowers extracts depending on the extraction conditions. Statistical analysis showed that between all presented values the differences were statistically significant.

For extraction 1 , statistically significant positive correlations between extraction time and antioxidant potential 


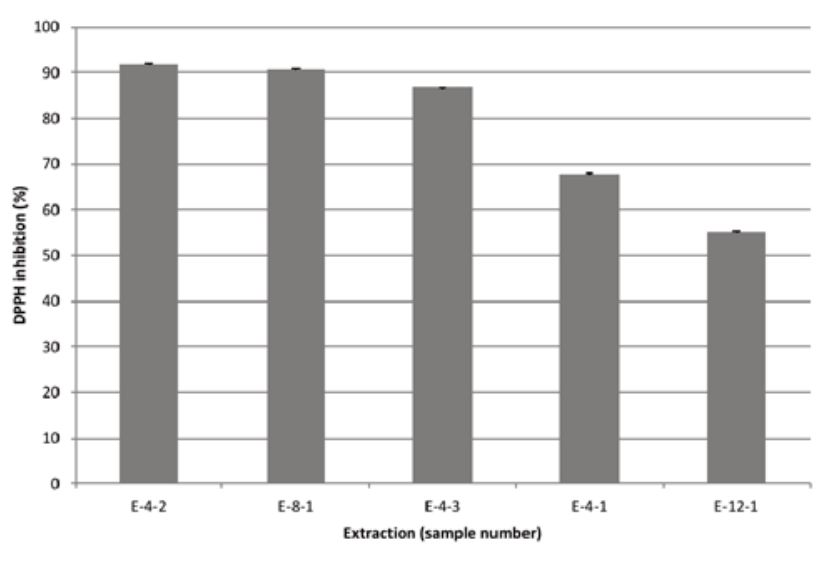

Figure 4. The comparison of antioxidant activity extracts of flowers of ground elder depending on the method of extraction (full explanation of the extract designations can be found in Table 1)

$\left(\mathrm{r}=0.58^{*}\right)$ and between extraction temperature and DPPH radical inhibition $\left(\mathrm{r}=0.72^{*}\right)$ were demonstrated for leaves extracts. This indicates that longer the time and temperature of extraction, the higher was the antioxidant activity of leaves extracts.

The same correlations were found for rhizome extracts. For the extraction 2, statistically significant correlations were found only for extracts from rhizomes, and in contrast to the previous ones, they were negative. The correlation between extraction time and antioxidant activity $\left(\mathrm{r}=-0.94^{*}\right)$ indicates that the longer extraction time, the lower was the antioxidant activity of the extract. The correlation between the extraction temperature and the antioxidant activity $\left(\mathrm{r}=-0.94^{*}\right)$ indicates that the higher the extraction temperature, the lower was the antioxidant activity of the extract. Differences in correlation may be related to a different content of compounds isolated from various parts of the plant.

The results of our research are consistent with the few studies of other authors. In Valyova et al. studies confirm that the choice of solvent determines the high antioxidant properties of this plant. Antioxidative potential of the extracts from goutweed was measured by spectrophotometric methods (ABTS, DPPH). Chloroform, ethanol and ethyl acetate were used as a solvent at the concentration $1 \mathrm{mg} \mathrm{ml}^{-1}$. For goutweed ethanol extracts exhibits the highest antioxidant potential in comparison to the other extracts $(\mathrm{EC} 50=66.135 \pm 1.6 \mu \mathrm{g}$ $\mathrm{ml}^{-1}$ ) (DPPH). The extracts prepared using chloroform and ethyl acetate showed weak antioxidant activity, less than $20 \%$ of inhibition of DPPH and ABTS radicals. It was thus confirmed that ethanol extract had higher antioxidative activity ${ }^{29}$.

Aegopodium podagraria L. contains polyphenols e.g. phenolic acids and flavonoids 9 , 14, 18, 30,31. Jakubczyk et al. showed that that the total content of polyphenols in the ethanolic extracts from different parts of Aegopodium podagraria L. depends on the morphological part of the plant and the temperature of extraction. The polyphenols concentration ranged from 6.3 to $34.5 \mathrm{ppm}$. The highest total polyphenol content was recorded for flower extracts, the lowest for seeds extracts. For leaves, rhizomes and seeds the highest content polyphenols was in extracts prepared at $80^{\circ} \mathrm{C}^{31}$. These studies also confirm that factors like the temperature or part of the plant determine the chemical composition of the plant, which may affect the antioxidant potential.

The leaves of this plant are characterized by a fairly high content of lipophilic antioxidants include carotenoids, chlorophylls, and tocopherols. Compared to spinach, with $138.72 \mathrm{mg}$ of total lipophilic antioxidants per $100 \mathrm{~g}$ fresh-weight basis, Aegopodium podagraria L. (146.07 mg $100 \mathrm{~g}^{-1}$ fresh-weight basis) had similar contents of total lipophilic antioxidants. The leaves had a high concentration of the xanthophylls lutein, neoxanthin and VAZ (the sum of violaxanthin, anteraxanthin and zeaxanthin) and total carotenes, slightly lower than the nettle ${ }^{32}$.

The results could be helpful in obtaining extracts from various parts of the plant. Shortening the extraction time (ultrasound) allows you to optimize the production process and obtain extracts with a high antioxidant potential. The studies shows that these extracts are a significant source of a natural antioxidant, which might be helpful in preventing the progress and treat of various oxidative damages. Despite several studies on antioxidative compounds and plant properties, further investigations are required to isolate and identify the antioxidant compounds present in the plant extracts.

\section{CONCLUSIONS}

The comparison the results obtained during the studies on the antioxidative properties of the extracts from various morphotic parts of the ground elder (leaves, rhizomes, seeds and flowers) obtained by different extraction methods: ultrasonic assisted extractions, extraction in the Soxhlet apparatus, extraction at the boiling point of the solvent used showed that all parts of ground elder can show radical scavenging activity, and it depends mainly on the method of extraction and extraction time. But the most beneficial is ultrasonic assisted extraction which used lower amount of solvent (ethanol) (weight ratio of plant material to ethanol 1:20). In case of all parts of the ground elder (leaves, rhizomes, seeds and flowers) it allows to obtain very high values of the antioxidant capacity (above 90\%) for very short extraction time amounted to 20-40 minutes. From two studied solvents ethanol turned out to be a better solvent.

Statistical analysis of the results showed that many factors influence on the antioxidant activity of the extracts. It was shown that both the morphological part of the plant and the extraction method were significant. The extraction parameters such as time, temperature, type of solvent and its amount were also important.

\section{ACKNOWLEDGEMENT}

The project is financed from the program of the Minister of Science and Higher Education under the name "Regional Initiative of Excellence" in 2019-2022 project number 002 / RID / 2018/19 amount of financing 12000000 PLN.

\section{LITERATURE CITED}

1. Benzie, I.F. \& Choi, S.W. (2014). Antioxidants in food: content, measurement, significance, action, cautions, caveats, and research needs. Adv. Food Nutr. Res. 71, 1-53. DOI: 10.1016/ B978-0-12-800270-4.00001-8. 
2. Valko, M., Leibfritz, D., Moncol, J., Cronin, M.T., Mazur, M. \& Telser, J. (2007). Free radicals and antioxidants in normal physiological functions and human disease. Int. J. Biochem. Cell Biol. 39, 44-84. DOI: 10.1016/j.biocel.2006.07.001.

3. Rahal, A., Kumar, A., Singh, V., Yadav, B., Tiwari, R., Chakraborty, S. \& Dham, K. (2014). Oxidative stress, prooxidants, and antioxidants: the interplay. Biomed. Res. Int. Article ID 761264, 1-19. DOI: 10.1155/2014/761264.

4. Chen, Z. \& Zhong, C. (2014). Oxidative stress in Alzheimer's disease. Neurosci Bull. 30(2), 271-281. DOI: 10.1007/ s12264-013-1423-y.

5. Gupta, R.K., Patel, A.K., Shah, N., Chaudhary, A.K., Jha, U.K., Yadav, U.C., Gupta, P.K. \& Pakuwal. U. (2014). Oxidative stress and antioxidants in disease and cancer: a review. Asian Pac. J. Cancer. Prev. 15(11), 4405-4409. DOI: 7314/ APJCP.2014.15.11.4405.

6. Hauser, D.N. \& Hastings, T.G. (2013). Mitochondrial dysfunction and oxidative stress in Parkinson's disease and monogenic parkinsonism. Neurobiol. Dis. 51, 35-42. DOI: 10.1016/j.nbd.2012.10.011.

7. Rains, J.L. \& Jain, S.K. (2011). Oxidative stress, insulin signaling, and diabetes. Free Radic. Biol. Med. 50(5), 567-575. DOI: 10.1016/j.freeradbiomed.2010.12.006.

8. Siti, H.N., Kamisah, Y. \& Kamsiah, J. (2015). The role of oxidative stress, antioxidants and vascular inflammation in cardiovascular disease (a review). Vascul Pharmacol. 71, 40-56. DOI: $10.1016 /$ j.vph.2015.03.005.

9. Cisowski, W. (1985). Flavonoid compounds in herb Aegopodium podagraria L. Herba Pol. 31 (3-4), 137-140.

10. Nowak, B. (2000). Leksykon roślin ozdobnych i użytkowych (wyd. 1). Warszawa, Polska: Wiedza Powszechna.

11. Stefanovic, O., Comic, L., Stanojevic, D., Čomić, L. (2009). Antibacterial activity of Aegopodium podagraria L. extracts and interaction between extracts and antibiotics. Turk. J. Biol. 33, 145-150. DOI: 10.3906/biy-0810-21.

12. Trąba, C., Rogut, K., Wolański, P. (2012). Wild plants and their use. Guide to selected species. Rzeszów, Polska: Procapathia.

13. Kunstman, P., Wojcińska, M. \& Popławska, P. (2012). Podagrycznik pospolity (Aegopodium podagraria L.) Post Fitot. 4, 244-249.

14. Orav, A., Viitak, A. \& Vaher, M. (2010). Identification of bioactive compounds in the leaves and stems of Aegopodium podagraria by various analytical techniques. Procedia Chem. 2, 152-160. DOI: 10.1016/j.proche.2009.12.022.

15. Priori, N.M., Lundgaard, N.H., Light, M.E., Stafford, G.I., van Staden, J. \& Jäger, A.K. (2007). The polyacetylene falcarindiol with COX-1 activity isolated from Aegopodium podagraria L. J. Ethnopharmacol. 113, 176-178. DOI: 10.1016/j. jep.2007.05.005.

16. Akhtardzhiev, K.H., Nakov, N. \& Nikolov, V. (1975). Content of flavonoids in Aegopodium podagraria. Farmatsiya. 25 (1), 24-27.

17. Kapetanos, C., Karioti, A. \& Bojović, S. et al. (2008). Chemical and principal-component analyses of the essential oils of Apioideae Taxa (Apiaceae) from Central Balkan. Chem. Biodivers. 5 (1), 101-119. DOI: 10.1002/cbdv.200890000.

18. Koyro, O.O. (2013). Role of goutweed (Aegopodium podagraria L.) biologically active substances in nephroprotective, hepatoprotective and hypouricemic activity. $\mathrm{PhD}$ thesis. Kharkiv - National University of Pharmacy. Ukraine.

19. Ojala, T. (2001). Biological screening of plant coumarins. Academic dissertation, University of Helsinki, Finland.

20. Paramonov, E.A., Khalilova, A.Z., Odinokov, V.N. \& Khalilov, L.M. (2000). Identification and biological activity of volatile organic compounds isolated from plants and insects. III. Chromatography-mass spectrometry of volatile compounds of Aegopodium podagraria. Chem Nat Comp. 36 (6), 584-586. DOI: $10.1023 / \mathrm{A}: 1017563708858$
21. Ojala, T., Remes, S., Haansuu, P., Vuorela, H., Hiltunen, R., Haahtela, K., Vuorela, P. (2000). Antimicrobial activity of some coumarin containing herbal plants growing in Finland. J. Ethnopharmacol. 73, 299-305. DOI: 10.1016/ S0378-8741(00)00279-8.

22. Tovchiga, O.V. (2009). The investigation of the goutweed (Aegopodium podagraria L.) diuretic, nephroprotective and hypouricemic action as the basis for the drug development. $\mathrm{PhD}$ thesis. Kharkiv - National University of Pharmacy. Ukraine.

23. Tovchiga, O.V. (2012). The influence of goutweed (Aegopodium podagraria L.) preparations on the metabolic processes in alloxan-induced diabetic mice. Pharmacol. Med. Toxicol. 5, 73-78.

24. Tovchiga, O.V. (2016). The influence of goutweed (Aegopodium podagraria L.) tincture and metformin on the carbohydrate and lipid metabolism in dexamethasone-treated rats. BMC Complement. Altern. Med. 16, 235. DOI: 10.1186/ s12906-016-1221-y.

25. Tovchiga, O.V., Shtrygol, S.Y., Taran, A.V. \& Yudkevich, T.K. (2016). The renal effects of the goutweed (Aegopodium podagraria L.) tincture and metformin in dexamethasone-treated rats. Clinical Pharmacy. 20 (4), 39-45. DOI: 10.24959/ cphj.16.1407.

26. Tovchiga, O.V. \& Shtrygol, S.Y. (2016). The effect of medicines with goutweed (Aegopodium podagraria $\mathrm{L}$.) on the physical endurance, cognitive functions and the level of depression in animals. News of pharmacy. 1 (85), 71-76. DOI: 10.24959/nphj.16.2100.

27. Tovchiga, O.V. (2017). The effects of goutweed (Aegopodium podagraria $\mathrm{L}$.) preparations on glycemia in intact rats and against the background of metformin. News of Pharmacy. 2(90), 54-62. DOI: 10.24959/nphj.17.2161.

28. Tovchiga, O.V. (2016). Interaction of Aegopodium podagraria L. (goutweed) preparations with central nervous system depressants. Ukrainian Biopharmac. J. 1 (42), 31-36. DOI: 10.24959/ubphj.16.6.

29. Valyova, M., Tashev, A., Stoyanov, S., Yordanova, S. \& Ganeva, Y. (2016). In vitro free-radical scavenging activity of Aegopodium podagraria L. and Orlaya grandiflora (L.) Hoffm. (Apiaceae). J. Chem. Technol. Metallurgy. 51 (3), 271-274.

30. Akhtardzhiev, K., Nakov, N. \& Nikolov, V. (1975). Content of flavonoids in Aegopodium podagraria. Farmatsiya. 25 (1), 24-27.

31. Jakubczyk, K., Kwiatkowski, P., Sienkiewicz, M. \& Janda, K. (2018). The content of polyphenols in extract from goutweed (Aegopodium podagraria L.) and their antistaphylococcal activity. Post Fitoter (1), 3-9, https://doi.org/10.25121/ PF.2018.19.1.3 (in Polish).

32. Šircelj, H., Mikulic-Petkovsek, M., Veberic, R., Hudina, M. \& Slatnar, A.(2018). Lipophilic antioxidants in edible weeds from agricultural areas. Turk. J. Agric. For. (42), 1-10. 